\title{
Bills of exchange as money: sources of monetary supply during the industrialisation of Catalonia, I $844-74^{1}$
}

\author{
XAVIER CUADRAS-MORATÓ \\ Universitat Pompen Fabra, Barcelona \\ and \\ JOAN R. ROSÉS \\ European Univensity Institute, Florence
}

The problem posed by the availability of means of payment has been of a central interest to historians analysing the process of industrialisation. For instance, T. S. Ashton found that bills of exchange constituted an important medium of exchange among industrial firms in Lancashire during the period $1790-1830^{2}$ A possible explanation for this is the need for large volumes of exchange media during periods of exceptional economic growth. In the Lancastrian case, the demand for money, arising from substantial numbers of commercial transactions, appears to have exceeded the available supply of currency. A similar development in Catalonia during the period $1844-74$ will be considered in the body of this paper.

New developments in monetary theory provide a microeconomic basis for understanding these historical episodes. In particular, the intention here is to analyse the mechanisms that allow the emergence of different media of exchange during periods of currency shortage, such as that experienced in Catalonia over the midnineteenth century. Theoretical search models of money explain how both market forces create their own mechanisms to facilitate exchange, and agents adopt conventions about the use of different means of exchange. The main implication arising from these kinds of model is that the basic characteristic of any good used as a medium of exchange is acceptability to the agents in the economy. Other intrinsic

${ }^{1}$ Different drafts of this paper were presented at the Quantitative Economic History Conference (Cambridge, England, Sep. I994), the Economic History Seminar, Universitat de Barcelona and the Economic and Business History Couference (Boulder, Colo., Apr. 1995). We wish to thank all participants, and an anonymous referec, for helpful comments; they, of course, have no responsibility for any remaining errors.

2 T. S. Ashton, 'The bill of exchange and privace banks in Lancashire, 1790-1830', Economic History Review, is (I945); and reprinted in T. S. Ashton and R. S. Sayers (eds), Papers in English Monetary History (Oxford, I953; reprinted 1954, 1967). 
characteristics of money, such as durability, homogeneity, etc., might be desirable but are unnecessary for a good to fulfil the role of medium of exchange.

The prime aim of this paper is to study the factors that made bills of exchange acceptable as means of payment when they were alongside other, more 'natural', exchange media, especially legal currencies. The data employed are drawn from the records of three different textile firms. Their entire accounts are available and indicate all sales, and the media of exchange used for their payment, during two years, 1859 and 1860 . As these data have been drawn from primary sources, they can be considered to be of exceptional accuracy. Moreover, the three firms were very different, in terms of technology employed, location and size.

The present interest lies in analysing the determinants of the acceptability of different types of bills as money and to consider their varying characteristics. It will be argued that the acceptability of a specific asset may depend on variables reflecting the nature of the particulat transaction giving rise to the debt and its commercial counterpart. A debatable point requiring clarification is: to what extent can bills of exchange be considered as money? On the one hand, it will be maintained that bills were taken as the means of payment for numerous dealings among firms but, on the other hand, it is clear that they were not accepted in all and every transaction. The obvious compromise reached is to consider bills of exchange, and other comparable documents, as media of exchange having restricted circulation within commercial networks.

In short, the main premise is that bills of exchange constituted money if agents wished to take them as such. The only requirement for an asset to be used as money would be its acceptability arising from agents so concurring in the market. Furthermore, it can be argued that monetary supply does not solely comprise legal status money. In particular contexts, individual agents' actions in the market will determine the amount and type of money. For this reason alone, the role of the supply of legal money should be given less importance than previously. For instance, while there was a great shortage of legal status currency in Catalonia during the period studied, this proved not to be an insurmountable obstacle in the way of marked economic growth, which contradicts other traditional explanations of the relationship between monetary supply and economic growth. Our analysis provides a possible framework explaining the possibility of economic growth despite restrictions in the supply of legal money.

Section 1 offers a brief, intuitive description of the theoretical arguments concemed with the nature of money as medium of exchange and which are germane to this investigation. The monetary and financial system in Catalonia during the mid-nineteenth century, the period of investigation, is outlined in section II. The uses of bills of exchange, and other documents, are illustrated and discussed in section III. In section IV, the database employed is described, following which an econometric test of our hypothesis is undertaken. The implications and possible extensions of our analysis are taken up briefly in the concluding section.
1

One of the recurrent questions in the economic literature about money is: what circumstances determine which objects will come to be used as generally accepted media of exchange? Although this is an interesting issue from a purely theoretical point of view, it has not aroused much attention amongst applied economists. This may be explained by most late twentieth-century economies relying on the generalised use of fiat money, issued with the legal backing of the political authorities of each country. However, this has not always been the case. As will be detailed below, economic historians have considered episodes in the past when different objects were used as media of exchange. ${ }^{3}$ Most of these occurrences were a result of the unconcerted market behaviour of many individual agents, being another outcome of their commercial relationships. Consequently, it is interesting to ask: what objects would come to be used as money, what determines this particular choice and what are the possible consequences of this at a more aggregated level? For instance, to develop further the third of these questions, how can this affect the definition of money supply and its relationship with economic development?

Surely the key, determining factor of the circulation of any type of medium of exchange is its acceptability. An object is more hikely to be estabhished as money if it is so regarded by many individuals within the economy. In this respect, one can say that acceptability has a self-reinforcing nature. It is not an intrinsic property of goods being used as medium of exchange but, rather, of the social conventions governing particular pattems of exchange between economic agents. This intuitive conclusion will hold for any object employed as medium of exchange. It will be the case whether the good is either an intrinsically worthless object - fiat money - or an object valued for consumption, or production, by some agents that, nevertheless, is accepted by further agents only for its exchange value and to be traded for other goods (commodity money)

These are not new notions in monetary theory since they were established by some of the first economists to explore the question of money. Thus Menger ${ }^{4}$ emphasised the concept of saleability (taken here as being synonymous with related notions, such as acceptability or marketability) of goods used as medium of exchange. The question arises: does this mean that any object could appear as money as long as there was some sort of social agreement about its acceptability as medium of exchange?

The previous discussion seems to overlook other aspects of money that have also received considerable attention from economists. In answering questions about the circumstances when a particular object may come to be used as a medium of

${ }^{3}$ An illustrative example of this is the literature concemed with the free-banking experience. See particularly: L. H. White, Free Banking in Britain: Theory, Experience and Debate, 1800-1845 (Cambridge, r984); idem (ed.), Free Banking (Aldershot, 1993); and K. Dowd (ed.), The Experience of Free Banking (London, I 1992 )

4 K. Menger, 'On the origin of money', Economic Joumal, 2 (1892). 
exchange, the importance of different objects' intrinsic properties has been stressed in order to assess the likelihood of them appearing as money. Jevons gave a list of the features required by any object to be suitable for performing the function of medium of exchange. ${ }^{5}$ Among others, he regarded portability, homogeneity, divisibility, stability of value, cognisability and indestructibility as necessary qualities of any commodity performing the role of money.

This alternative explanation about the characteristics of money could be seen as somewhat contradictory with the previous account that stressed the conventional aspect of money but only highlighted the acceptability aspect of the media of exchange. The arising questions to be answered are: can any good emerge as a medium of exchange provided that there is a sufficiently extended social agreement about its role? Or, on the contrary, do specific intrinsic properties of goods preclude them from becoming generally-accepted media of exchange? Recent developments in the theory of money, using concepts from search theory and modern dynamic economic modelling, illustrate this trade-off between endogenous acceptability and intrinsic properties. They help to provide satisfactory answers to such questions. The principal conclusions of these models will be described, in conjunction with examining the insights they provide for the analysis of the particular problem posed here.

Most models in monetary economics have focused on finding equilibria in which an object, previously and exogenously determined as money, has a positive price. In other words, the object is considered valuable by individuals to perform the role of medium of exchange. However, search theoretical monetary models ate, in many senses, models of currency choice, in which the commodity used as money is determined as part of the model's equilibrium. Thus their crucial feature is that they provide a framework in which the determinants of the circulation of different objects as media of exchange are analysed endogenously. ${ }^{6}$

Search theoretical models of money study decentralised economies, in which agents take decisions independently. Nevertheless, in equilibrium, some mechanisms of coordination of monetary exchange appear. Thus, whenever an agent has to decide about exchanging a good currently being held for another good that is not a consumption good (that is, a good to be used as medium of exchange), two things must be evaluated. The first is the marketability of the good, which is something determined jointly by the trading strategies of all agents in the economy and, moreover, which is precisely what makes a particular good more or less acceptable. The second is the particular intrinsic characteristics of this good that makes it more, or less, costly to hold in an inventory. Goods can be more, or less, storable since they have different durabilities and the risk arises that they may perish before they

${ }^{5}$ S. Jevons, Money and the Mechanism of Exchange (London, 1875).

- The basic references are: N. Kiyotaki and R. Wright, 'On money as a medium of exchange', Joumal of Political Ecotomy, 97 (1989); R. Wright, 'Search, evolution and money', Joumal of Economic Dynamics and Control, 19 (I995); and X. Cuadras-Morato, 'Commodity money in the presence of goods of heterogeneous quality', Economic Theory, 4 (I994). can be disposed of. Equally, they might be of heterogeneous quality, etc. In other words, a good might be very acceptable and, as a consequence, have a liquidity advantage, even if it is relatively costly to hold. Yet, on the other hand, goods with relatively low costs could be less acceptable in equilibrium because of agents' particular trading strategies. The equilibria and their characteristics will depend precisely on the joint interaction of all these factors while the different media of exchange used by agents in this economy are determined endogenously in equilibrium. It can be put forward that these types of theoretical constructs constitute natural devices for analysing the specific endogenous choice of media of exchange made by agents in the economy.

What are the implications of these models for the specific historical problem being studied in this paper? As will be shown below, neither commodity money nor fiat money are being examined but, rather, some other objects, namely documents such as promissory notes and bills of exchange. It will be argued that they circulated as media of exchange among firms during Catalonia's industrialisation. The aim is to understand the reasons that give individual entrepreneurs the incentive to accept some particular objects as media of exchange in a specific historical context. $\ln$ order to do so, some of the conclusions derived in search theoretical models are applied to the type of situation encountered by an individual firm. The firm must decide about whether accepting, or not, some privately-issued document as a medium of exchange. It will be argued that the probability of its acceptance by a particular firm, together with the particular features of the object used as money, will be determined by the nature of the transaction and the characteristics of both the trading partner and the market in which agents interact.

A first determining factor regarding the acceptance of documents, other than money, is the general context within which the entrepreneurs operate. The relative scarcity of flat money will cause the progressive substitution of this kind of medium of exchange. Other objects will come to be used by agents in payments for their transactions, depending on their relative abundance and the willingness of other agents to accept them. Consequently, there is a need for some localisation variable which may control for this effect in the empirical model put forward.

Second, variables must be included in the model that may indicate whether there is a long-term commercial relationship between a firm and a particular customer. This arises because we believe that firms will take documents proffered by different customers as distinct objects. In turn, this is due to there being a reputation effect, with it being likely that long-term customers are considered to be 'good quality' chents. Consequently, they will be allowed to pay with privately-issued documents, such as bills of exchange or others. This is a variant to theoretical models, in which interaction takes place among anonymous agents and no allowance is made for reputation effects. However, in framing the model in more realistic terms, firms clearly have different types of customers who can be readily identified and, as a consequence, this must be taken into account. One way to make allowance for this feature is to put forward the hypothesis that different customers pay their debts with 
documents which are considered to have differing qualities by their creditor firms. Quality is related to the different information and degrees of trust that the creditor firm has about its customers and is related to the notion of reputation.

Finally, some consideration is paid to the choice of documents with different intrinsic qualities offered to creditor firms. In particular, the choice between documents to be paid before a given date and those without this restriction is modelled in order to analyse the determining factors of this election.

\section{II}

The Catalan economy grew very rapidly during the period I $844-74$, leading to it becoming the first Spanish industrial region and one of the most important on the European continent. The main industry by far was cotton textiles. It completed its mechanisation over the mid-nineteenth century and, thereby, obtained some important improvements in productivity. At the same time, modern transport networks were built, most notably railways, while sizeable towns grew up. This transformation, which occurred over a relatively short period of time, relied almost exclusively upon domestic capital supplies. Furthermore, over this period, Catalonia had a sizeable balance of trade deficit with the rest of the world due to substantial imports of technology and raw materials, mainly coal and cotton. ${ }^{7}$

The financial system also underwent a series of important changes. Before the mid- 183 os there were only a small number of private bankers but, in 1842 , legislative reform allowed banks to be established as limited liability companies. ${ }^{8}$ Furthermore, some of these incorporated banks were granted local note-issuing monopohes although their notes were only legally valid within the towns where they were issued. One of these banks, the Banc de Barcelona, was established in 1844. ${ }^{9}$ Two other, but less important, banks were founded in the Catalan towns of Reus and Tartagona in 1862 and 1864 respectively. Furthermore, several different banking corporations were created in Barcelona in 1855 , some of which were similar to sociétés de crédit while others were comparable to commercial banks. However, many of these new banks were adversely affected by the 1866 financial crisis. The mid-century period ended with a major change in 1874 , when the Banco de España was granted the monopoly of the issue of legal currency for the whole of Spain, so ending the system of multiple local monopolies.

The main sources of currency had been Spain's trading surplus with its American colonies and the direct transfer of taxes from the colonies. However, Spain had a significant trading deficit with the rest of the world, which led to a sizeable share of

7 The major literanure on the Catalan industrialisation comprises: J. Nadal, El fracaso de la revolución industrial en España (Barcelona, I974); and J. Maluquer, 'La revolución industrial en Cataluña', in N. Sánchez-Albornoz (ed.), La Modemización Económica de España (Madrid, 198s).

B G. Tortella, Los Orígenes del Capitalismo en España (Madrid, 1973).

9 For the history of this bank, see F. Cabana, Història del Banc de Barcelona (1844-1920) (Barcelona, 1978).

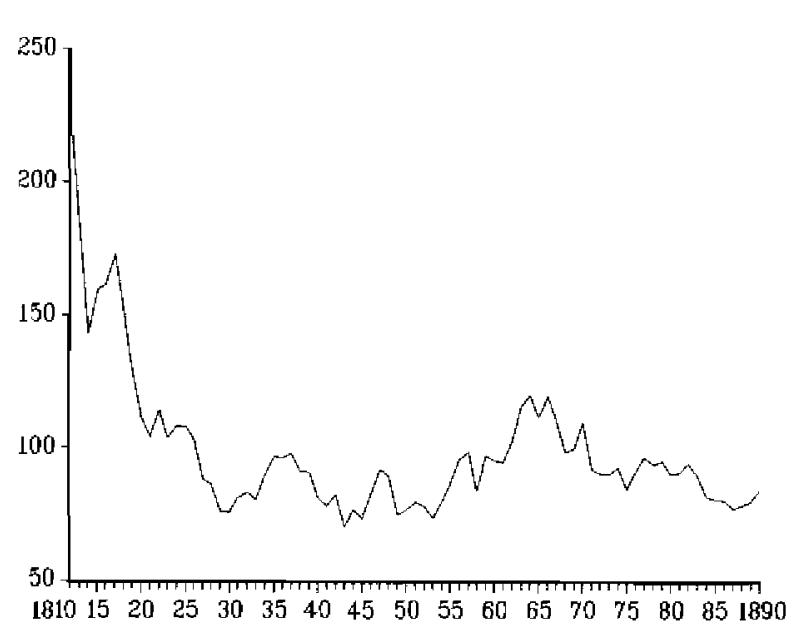

Figure I. Barcelona wholesale price index, 1810-90 $(1913=100)$

the currency arriving from America being re-exported to settle international debts. Furthermore, the Convention and Napoleonic wars and the loss of the colonies in America resulted in a difficult situation regarding new imports of bullion for offsetting the already chronic Spanish trading deficit. The main consequences of these disruptions of the early nineteenth century were the progressive loss of gold and silver and a considerable reduction of the domestic money supply. This led to the whole economy experiencing a deep deflationary crisis during the first three decades of the nineteenth century (see Figure 1 ).$^{10}$ Consequently, the monetary system in Spain during this period became very complex, although addressed by successive reforms. ${ }^{\mathrm{t}}$

Between I 830 and I 874 , different governments implemented legislation dealing with the monetary problem. The most important reforms took place in 1842,1848 and 1864 but these measures were not successful, being insufficient to establish sources of stable monetary supply. This was due to a number of reasons. First, there were several frustrated attempts to create new and definitive monetary units: reales de vellón, escudos and duros. All failed because the govemment was unable to amass enough gold and silver for minting sufficient coinage. Furthermore, they produced

${ }^{10}$ For a recent review of this point, see P. Pascual and C. Sudrià, Quiebra colonial y ajuste monetario en España, mimeo (I992); while a critical view can be found in L. Prados, 'El comercio exterior, I792-I827. La pérdida de las colonias americanas y sus efectos sobre la economía española', in J. Fontana (ed.), La Economía Espafiola al final del Antiguo Régineen. III. Comercio y Colonias (Madrid, I982).

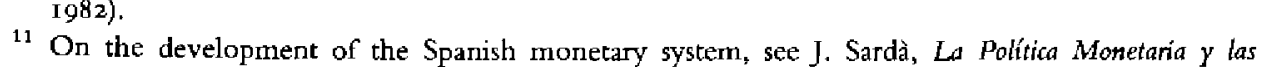
Fluctuaciones de la Economía Española en el siglo XIX (Madrid, I948); G. Tortella, 'Las magnitudes monetarias y sus determinantes', in P. Schwartz (ed.), La Banta Española en la Restauracónn, 2 vols (Madrid, I974); and idem, 'Los sistemas monetario y bancario', in M. Tuñón de Lara (ed.), Historia de Esparia (Barcelona, 198r). 
Table 1. Fiat money issued in Catalonia until the end of 1858

\begin{tabular}{llrr}
\hline \hline Type & \multicolumn{1}{c}{ Issued by } & Duros & \% of total \\
\hline Bank notes & Banc de Barcelona & $2, \mathbf{1 2 4 , 2 7 5}$ & 32.56 \\
Bitllets-Calderilla & Diputació de Barcelona & $1,739, \mathbf{1 2 3}$ & 26.65 \\
Talons registrats & credit and commercial banks & $636,38 \mathbf{I}$ & 9.76 \\
Obligacions & credit and commercial banks & $2,024,250$ & 31.03 \\
Total & & $6,524,029$ & 100.00 \\
\hline \hline
\end{tabular}

Source: P. Pascual and C. Sudrià, Qniebra colonial y ajuste monetario en España, mimeo (1992).

a complicated and confusing monetary system due to multiple coexisting monetary units. Second, the creation of different issuing banks proved not to be totally successful. In Catalonia, for instance, although it might be thought that the presence of the Banc de Barcelona in the money market would solve, at least partially, some of the regional economy's problems, it actually proved otherwise. This was because the bank's management adopted very conservative policies and maintained substantial amounts of capital in reserve through searching for greater stability. The bank's behaviour was such that, through holding so large reserves, at the worst moments of the economic cycle its net contribution to the creation of monetary supply was negative. ${ }^{12}$

During I 852 new fiat money was added to the issues of the Banc de Barcelona. This arose from the government deciding to substitute new coins, calderilla castellana, for the old copper coins minted in Barcelona. The latter were the same as copper coins traditionally used elsewhere in Spain but with a different weight and value. However, the government lacked sufficient coins to make a complete substitution and, as a consequence, had to issue notes to cover the difference. These had redemption dates as they were to be progressively replaced by the new coins. It was required that the notes were used for transactions with the government. In addition, the legal regulations laid down that a fixed percentage of any private debt could be paid in these notes. Nonetheless, the notes found less acceptability amongst the public than either those issued by the Banc de Barcelona or the metallic currency. Consequently, they fell below their par value.

In addition, from I 855 , the new banking companies issued other types of financial instruments in order both to attract new capital and circumvent the Banc de Barcelona's note-issuing monopoly. These took the form of bonds and cheques, obhigacions al portador and talons registrats, which were used by the public as means of payment (see Table I). Obligacions al portador were bonds issued by the banks that had to be paid to the bearer at the office of the issuing bank in metallic currency. Talons registrats were private notes created by the board of directors of a

${ }^{12}$ J. R. Rosés, Banca i indústria a Catalunya, I844-1874, M.A. thesis (Uriversitat de Barcelona, I993). bank and backed by the same bank, which had to be paid to the bearer under the same circumstances. Although these documents were sometimes called bitllets [notes], this type of money had no legal standing. Some agents accepted these instruments as payment for relatively important transactions, such as stock market dealings, but they were seldom used in daily commercial operations.

As Figure $I$ indicates, between 1844 and 1874 the price level in Catalonia rose slightly at 0.64 per cent per annum. Analysing different sub-periods indicates that there is some correlation between the changes in the financial system and the movement of prices. The absolute monopoly of the Banc de Barcelona from I 844 to 1855 resulted in a low inflation rate ( 1.07 per cent). The following period, $1855-66$, when more corporate banks were active in the market, is characterised by a much higher inflation rate $(3.04$ per cent). The period after the crisis of 1866 (1 866-74) is distinguished by a relatively important deflation rate ( -3.14 per cent).

Following Milton Friedman ${ }^{13}$ on bimetallism, it might be thought that this particular monetary regime gave rise to general price stability. Nevertheless, it will be argued that this was not necessarily so in the Spanish case because the volume of gold and silver in circulation was found to be very small. ${ }^{14}$

To sum up so far. The following elements in the mid-nineteenth Catalan experience have been found: rapid economic growth in a very short period of time, a significant international trading deficit met by exports of specie, price stability and, finally, an apparent shortage of currency. Their conjunction seems to contradict standard macroeconomic theory. We argue that a possible explanation to this puzzle lies in the use of bills of exchange, and other privately-issued documents, as means of payment, probably due to the shortage of other alternative media of exchange.

\section{III}

Bills of exchange and similar instruments had been used in international transactions in continental Europe since at least the thirteenth century and Catalonia was no exception. For a long time, their use was regulated by commercial practice. During the eighteenth century, somewhat like legal developments in England, the Consulats de Comerç [local associations of merchants created under royal patronagel of several towns made various rulings governing the creation, and use, of bills of exchange and similar instruments. Nevertheless, the definitive basis for the regulation of these types of financial instrument was not established until I82 I with the promulgation of the first Spanish Code of Commercial Law. This new legal code allowed the homologation of their use in trading relationships.

The Spanish Code was modelled upon the French Code, so that it was very detailed. Bills of exchange were defined as contracts involving a private promise of payment. Generically, the Code established two basic types of bills: those that had

${ }^{13}$ M. Friedman, Money Mischief. Episodes in Monetary History (New York, 1992)

${ }^{14}$ Tortella, 'Las magnitudes monetarias'. 
to be paid within a specified number of days after their presentation (e.g. eight days), but with their tenure limited to a maximum of 40 days; and those that had to be paid on a particular date (e.g. 24 February I 834 ). The bill need not be signed by the drawee and, consequently, many were incomplete contracts. Nonetheless, in these instances, the drawee had the legal responsibility for the payment of the bill. This legal framework also defined other different types of documents. Promissory notes [pagarés] were considered to be bills signed by the debtor and were legally enforceable only in the towi where they had been issued. These were much safer instruments from a legal point of view because their ultimate enforcement might involve the seizure of real estate. There were also cartes-ordre, which were similar to bills of exchange but legally valid only in the town where they had been issued.

Initially, bills of exchange were created as instruments to make transfers between merchants located at different places. In particular, when a customer located outside Catalonia wanted to cancel a debt, he would buy a bill against a firm in an important financial centre in Spain or Catalonia and send it to his Catalan creditor. The demand for bills of exchange varied, depending on their place of origin with, during this period, the Spanish financial market not being integrated. For these reasons, the prices for bills could vary. ${ }^{15}$

An example of the use of the bill of exchange to make a transfer is illustrated in Figure 2. It begins with a Catalan entrepreneur sending cotton textiles to another tradesman in Málaga. In order to cancel the arising debt, the Málaga merchant required currency that is valid in Barcelona. He obtained a bill of exchange against Barcelona from his banker, which he dispatched to his supplier. Finally, the bill was 'extinguished' by the signature of the final holder of the bill and was returned to the original drawer.

The developing use of bills of exchange led to them becoming, at some moment of time, instruments of credit and a medium of exchange. In Spain, both bills of exchange and promissory notes could be used as credit instruments. However, the bill of exchange was an incomplete contract because it was seldom signed by the debtor while the promissory note was a complete contract as it always had to be signed by the borrower. The merchant banker bought a bill from the local trader as the basis for lending money to him. Thereafter, this bill was negotiated and went from one town to another, being used as a medium to transfer money. Finally, it was encashed on its expiry date by the last holder with the borrower paying its value.

The use of promissory note was clearer in the sense that the borrower was always liable for the debt. Figure 3 illustrates the employment of promissory notes as instruments of credit. For instance, an industrialist sold cotton yam to a cottonweaving firm. This firm's fabrics were then sold to yet another firm which printed

15 L. Castañeda and X. Tafunell, 'Un nuevo indicador para la historia financiera española: la cotización de las letras de cambio a corto plazo', Revisto de Historia Económica, I I (1993); and L. Castañeda, 'Crédito y mercado monetario no bancario en Barcelona a mediados del siglo XIX. Algunas consideraciones sobre la pervivencia de instrumentos financieros tradicionales', $V$ Congreso de la Asociación de Historia Económica (San Sebastián, 1993).

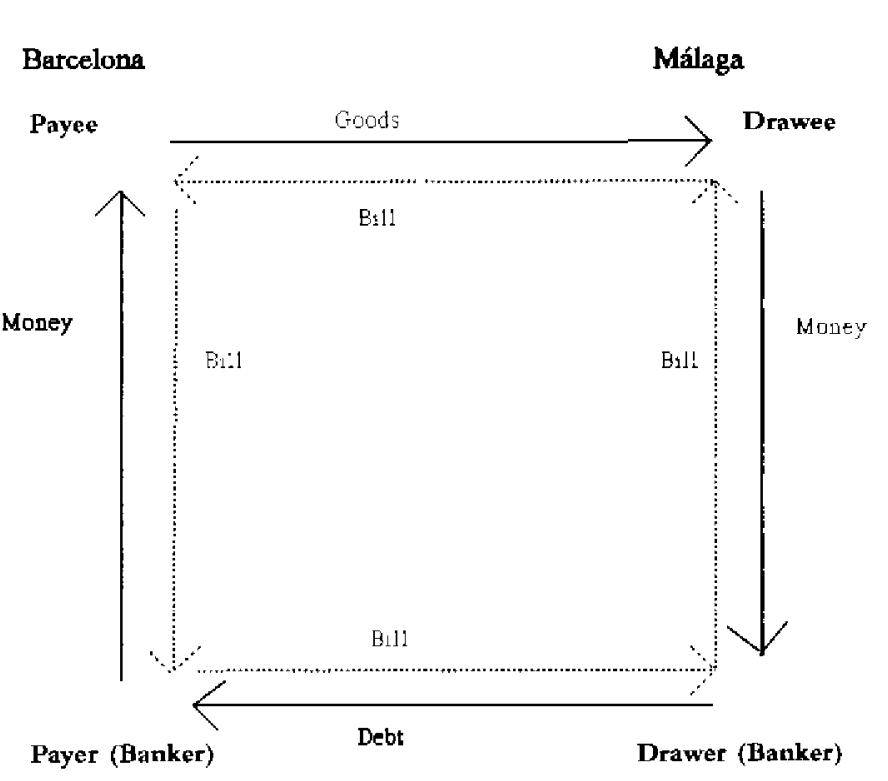

Figure 2. The use of bill of exchange as a medium of transfer money

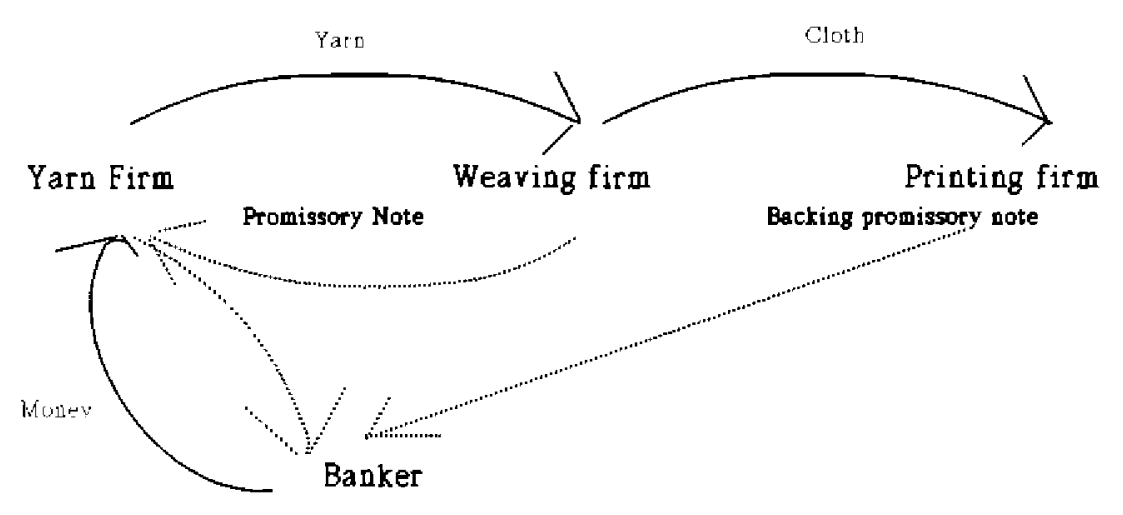

Figure 3. The use of promissory note as an instrument of credit

them. The initial production of cloth was financed by the yarn firm through an open credit. After 90 days of open credit, the weaving furm signed a promissory note which was backed by the printing firm. The promissory note was retained to the day that it had to be redeemed, or was discounted at a bank or, finally, could be used as medium of exchange. Summing up, the promissory note was part of a general contract of sale and credit.

However, the main use of the bill of exchange in Catalonia during the midnineteenth century was as a medium of exchange. A representative case can be seen examining the relationship between Pere Turull (details of this merchant's commer- 
cial activities are given below when our database is described) and Antoni Gali $\mathbf{i}$ $\mathrm{Cia}$, one of his best customers. Both families were in the wool trade and had known each other for more than a half of a century. Antoni Gah had become one of the most important Spanish woollens manufacturer and bought a great deal of the raw wool from Pere Turull. Gali was given credit for more than one year for his purchases of wool from Turull. He paid when it was convenient for him to do so, and Turull accepted that almost all of these payments would take the form of the transfer of bills of exchange issued by third parties. These bills were obtained by Gali in payment for his own commercial operations. Turull was aware that some of these bills would not be met but trusted GaK to take charge of them. Thus the reputation of the customer (who passed the bill to the firm) was far more important that that of the final debtor (who was ultimately responsible for the debt). Turull could do one of three different things with the bills he took from his customers. $\mathrm{He}$ could pass them to another firm to cancel some debt; or he could sell them to his Barcelona banker; or, and exceptionally, he could try to receive payment directly from the final debtor of the bill.

We argue that the main use of bills of exchange was as a medium of exchange. This can be justified by looking at the accounts of the firms for the period of this study. The vast majority of bills, and other documents, accepted by these firms were passed on to meet their own obligations, that is, they were used as a means of payment. For instance, Miquel Puig's accounts show that, in I 860, only two bills of exchange were discounted at a bank while the other $\mathrm{I} 47$ were given to different firms to pay commercial debts. The same practice can be found in the affairs of Pere Turull, whose volume of trade undertaken via the circulation of bills of exchange was much greater. Nearly all the bills that he took in payment for his sales were used to discharge his debts since he only used other means of payment than credit docurnents in 17 , out of 696 , payments for purchases.

Economic growth arising from industriahsation caused an increase in the number of both commercial transactions and agents in the markets. Consequently, the amount of bills in the market and their use grew at a rapid rate. For this reason, the bill of exchange became less secure as payment but, at the same time, more acceptable because of its generalised circulation. Anyway, its non-payment and negotiation were costly. This was due to the lengthy and expensive formal requirements that had to be met when making a legal claim for the payment of a bill.

A typical bill of exchange was created when a commercial transaction gave rise to a debt between two firms. The seller drew the document against the buyer, but incurred the ultimate legal responsibility for it whenever the final debtor did not accept the bill. Usually, the seller would pass the document to another firm to meet a debt, while the receiving firm normally had no connection with the original transaction. This third firm could also pass the bill to a fourth firm and, eventually, the bill would be paid by the final debtor against whom it was drawn. If the final debtor did not accept the bill, each one of the agents who had accepted it could make a claim for the payment against the firm which had passed it to them.
Obviously, the final responsibility for the payment of the debt was with the firm who initially drew the bill of exchange. Consequently, only reputation, confidence and continuity of exchanges made the use of bills of exchange an efficient means of payment.

To sum up. Whereas bills' intrinsic qualities were unfavourable for their use as efficient media of exchange, nonetheless the existence of commercial informal networks made this not only possible but also economically advantageous. Bills of exchange were instruments of payment for agents inside these networks. Within business circles, the only requirement for taking a bill of exchange as money was to know and trust the agent who offered it. This was sufficient to make the bill acceptable as means of payment. Hence, it was unnecessary to know the person who had to pay the bill in the last instance. By necessities of business, agents within these networks were very interested in sustaining long-term commercial relationships and, consequently, had to sustain their individual reputations by honouning their obligations. Moreover, it was not easy to penetrate these networks. An unknown entrepreneur would be asked for a good reference or even a guarantee before being accepted as a regular customer.

IV

The objective of this section is to provide some empirical evidence concerned with individual decision-making in the choice of media of exchange. Aggregate data do not provide much information for such an analysis. However, the availability of new micro-historical data allows its examination from an entirely new perspective. Using material gathered from the accounts of several Catalan textile firms for the period $1859-60$, an econometric relationship is put forward, based on the theoretical intuitions described in the models that have been previously explained. In particular, we present two different models in trying to identify the most relevant variables that explain the type of medium of exchange used in the different commercial transactions of the firms that have been analysed.

The entire database for the analysis was constructed by looking directly at the accounts of three different firms. Each observation corresponds to a payment operation for a previous sale made by the firm. In other words, each data-point describes several characteristics of these transactions and the media of exchange used to complete them. Moreover, the specific characteristics of the customers involved in each of the operations are considered.

The three firms were involved in the textile industry, the most important within manufacturing in Catalonia during the mid-nineteenth century. Furthermore, the three firms can be considered to be representatives of three different branches within the Catalan textile industry: Pere Turull - raw materials; Miquel Puig i Cia - intermediate products; and Societat Puig - final products.

Pere Turull, a specialist in the wool trade, was located in Sabadell, approximately 3o km. from Barcelona, which was the main Spanish centre of wool textile pro- 
duction. The firm was very important, controlling more than 40 per cent of the wool trade in Sabadell, and most of its customers came from the town or its immediate area. The volume of commercial intercourse was affected by the amount of legal currency available in Sabadell being very scarce in relationship to that required by a growing economy. This was due to there being no local commercial banking institutions and a lack of direct links with financial institutions in Barcelona. As a result, for instance, employers in Sabadell paid workers with privately-issued notes, which did not have any legal backing but were accepted by the town's shopkeepers. Pere Turull sold wool by giving open credit to its customers that had no supporting documentation. These debts were discharged by Pere Turull taking as payment either legal currency or some other documents, such as bills of exchange drawn by a third party. In these instances, the bills were neither credit nor transfer instruments but a means of payment. ${ }^{16}$

Miquel Puig i Cia was the sixth largest industrial firm in the Catalan cotton industry, producing yarn and coarse fabrics which were sold to other Catalan manufacturers. Although its factory was in Esparreguera on the banks of the river Llobregat, all its business affairs were conducted at its main office in Barcelona. ${ }^{17}$ The third firm, Societat Puig, printed cotton in Sants, Barcelona and sold finished cloth. ${ }^{18}$ The relationships that these two firms had with their respective customers were similar to those of Pere Turull.

Table 2 shows the means of payment received by three firms in order to meet debts. It should be noticed that the use of documents as means of payment was more important than legal currency. Moreover, bills of exchange were the most common documents while unsigned documents were used more regularly than signed documents.

The methodology used in the analysis of the data is the logit analysis. This procedure allows the estimation of the probability of an event occurring, given a sample of different explanatory variables. Specifically, given that the dependent variable is dichotomic (in the case of the first model, it indicates whether a transaction is completed with legal currency or some other document), the logit estimates a non-linear equation that indicates the determinant factors of a dichotomic event. ${ }^{19}$

In the first model, it is assumed that several factors determined the decision to pay for transactions with either legal currency or some other document. There was insufficient currency circulating in the market to satisfy the needs of agents to complete their transactions. This situation was especially important in the case of firms that were not in Barcelona and so did not have immediate access to formal banking institutions. As a result, they experienced gteater difficulty acquiring legal

${ }^{16}$ Arxiu Històric de Sabadell, Sabadell: Fons Pere Turull, Account and letter books, I $859-60$.

17 Arxiu Nacional de Catalunya, Barcelona [hereafter ANC]: Fons Sedó - Empresa Miquel Puig i Cia, Account books, I $859-60$.

19 ANC: Fons Sedó - Societat Puig, Account books, 18 $59-60$

19 For the econometric issues, see W. Greene, Econometric Analysis (New York, 1993).
Table 2. Transactions in the sample classified by means of payment

\begin{tabular}{|c|c|c|c|c|}
\hline \multirow[b]{2}{*}{ Type } & \multicolumn{2}{|c|}{ Operations } & \multicolumn{2}{|c|}{ PTA } \\
\hline & Number & $\begin{array}{c}\% \text { of total } \\
\text { number }\end{array}$ & value & $\begin{array}{c}\% \text { of total } \\
\text { value }\end{array}$ \\
\hline Currency & 858 & $4 \mathrm{I} .73$ & $1,622,852$ & $39-9 \mathrm{I}$ \\
\hline Documents* & $\mathrm{I}, \mathrm{I} 98$ & $\$ 8.27$ & $2,443,57$ I & 60.09 \\
\hline Total & 2,056 & {$[00.00$} & $4,066,423$ & 100.00 \\
\hline \multicolumn{5}{|c|}{ ॠ(i) documents only, of which: } \\
\hline bills of exchange & $I, 106$ & 92.32 & $\mathrm{I}, 8 \mathrm{0} 3, \mathrm{I} 78$ & 73.79 \\
\hline others & 92 & 7.68 & 640,393 & $26.2 \mathrm{I}$ \\
\hline Total & $\mathrm{I}, \mathrm{I} 98$ & 100.00 & $2,443,571$ & 100.00 \\
\hline \multicolumn{5}{|c|}{$\star$ (ii) documents only, of which: } \\
\hline signed & 193 & I $6 . \mathrm{I} I$ & $866, \mathrm{I} 73$ & 35.45 \\
\hline unsigned & $I, 005$ & 83.89 & $1,577,398$ & 64.55 \\
\hline Total & $\Upsilon, \mathrm{I} 98$ & 100.00 & $2,443,57 \mathrm{I}$ & 100.00 \\
\hline
\end{tabular}

Source: see text.

currency which led to the use of alternative means of exchange to make payments. At the same time, there is a need to control for the intrinsic characteristics of the transactions that may influence in the choice of means of payment.

The dependent variable is dichotomic and takes the value zero when the debt originated by the transaction was cancelled with legal currencies such as gold and silver coins, notes issued by the Banc de Barcelona and bitllets de calderilla catalana It takes the value one when the debt was cancelled with some other documents: bills of exchange, promissory notes, bonds and similar instruments.

The main hypothesis can be expressed by the following model:

$\operatorname{Prob}($ Document $=\mathrm{I})=\mathrm{f}(\alpha+\beta \mathrm{BCN}+\gamma \mathrm{EsP}+\delta \mathrm{CAT}+\varepsilon \mathrm{NuM}+\zeta$ Pur $+\mu)$

This model means that the probability that payment was made without legal currencies is a non-linear function of the following variables:

$\mathrm{BCN}$, a dichotomic variable that takes value I if the firm to which the payment was made was located in Barcelona (Societat Puig) and value o otherwise;

EsP, also a dichotomic variable which takes value I when the firm to which the payment was made was located in Esparreguera (Miquel Puig i Cia) and o otherwise;

$\mathrm{CAT}_{\mathrm{A}}$, a dichotomic variable that takes value I when the customer who paid for a transaction was located in Catalonia, and o otherwise;

Num, a variable which measures the number of transactions that took place during $1859-60$ between the customer and the firm who were the subjects of each transaction; 
and PUR, a variable which measures the total value of the purchases (in pesetas) that took place during $1859-60$ between the customer and the firm subject of each transaction.

The expected outcome for our analysis was that the probability of payment taking place without legal currency was a positive function of the variables Num and Pur, and a negative function of the variables BCN, Esp and CAT. It was expected that Num would be positively related with the dependent variable because a sizeable number of transactions between two agents indicates a closer, long-term commercial relationship between them and, consequently, a higher level of business confidence. This reputation effect would explain why bills of exchange (or other documents) were easily accepted instead of universally acceptable legal currencies. Likewise, Pur was also expected to be positively correlated with the dependent variable. This is because a larger value of this variable can be considered to signal a better 'quality' of the customer involved in the transaction. Obviously, good quality customers could get documents, besides legal money, more easily accepted than other customers. In a sense, there are two different variables which may be indicative of a reputation effect. One is the number of transactions between firm and customer, which shows the existence of an ongoing relationship with frequent commercial agteements. The other is the total value of the transactions between customers and firms which indicates the relative importance of the customer and may influence his ability to pay with instruments other than legal money.

The estimates of the coefficients of the three dichotomic variables were expected to be negative. Variables ESP and BCN were expected to be negatively correlated with the dependent variable because the supply of legal money in Sabadell was comparatively smaller than in the other two markets and, consequently, transactions involving a finn located there imply a higher probability of payment with a document other than fiat money. Likewise, variable $\mathrm{C}_{A T}$ was expected to have a negative estimated coefficient. This is basically because finns placed outside Catalonia had greater difficulties finding legal currency with which to pay because elsewhere the formal financial system was even less developed than in Catalonia. In addition, it was easier during the mid-century to transfer bills of exchange than coins. It should be remembered that bank notes only circulated in the area around their place of issue while promissory notes could only be legally enforced in the town where they had been signed. Such a context made it more likely for firms located outside Catalonia to have documents accepted as payment for their debts.

The results of the estimation of the first model are summarised in Table 3. All the estimated coefficients of the variables have the expected signs and are significantly different from zero (as shown in column Signif.). Looking at the $\mathbf{R}$ column, it can be seen that variables EsP and BCN make a similar partial explanatory contribution to the model and are the most relevant variables. This is clearly indicative that restrictions on the monetary market were relatively important in the choice of media of exchange by firms. Notice that the other variables are significant but their

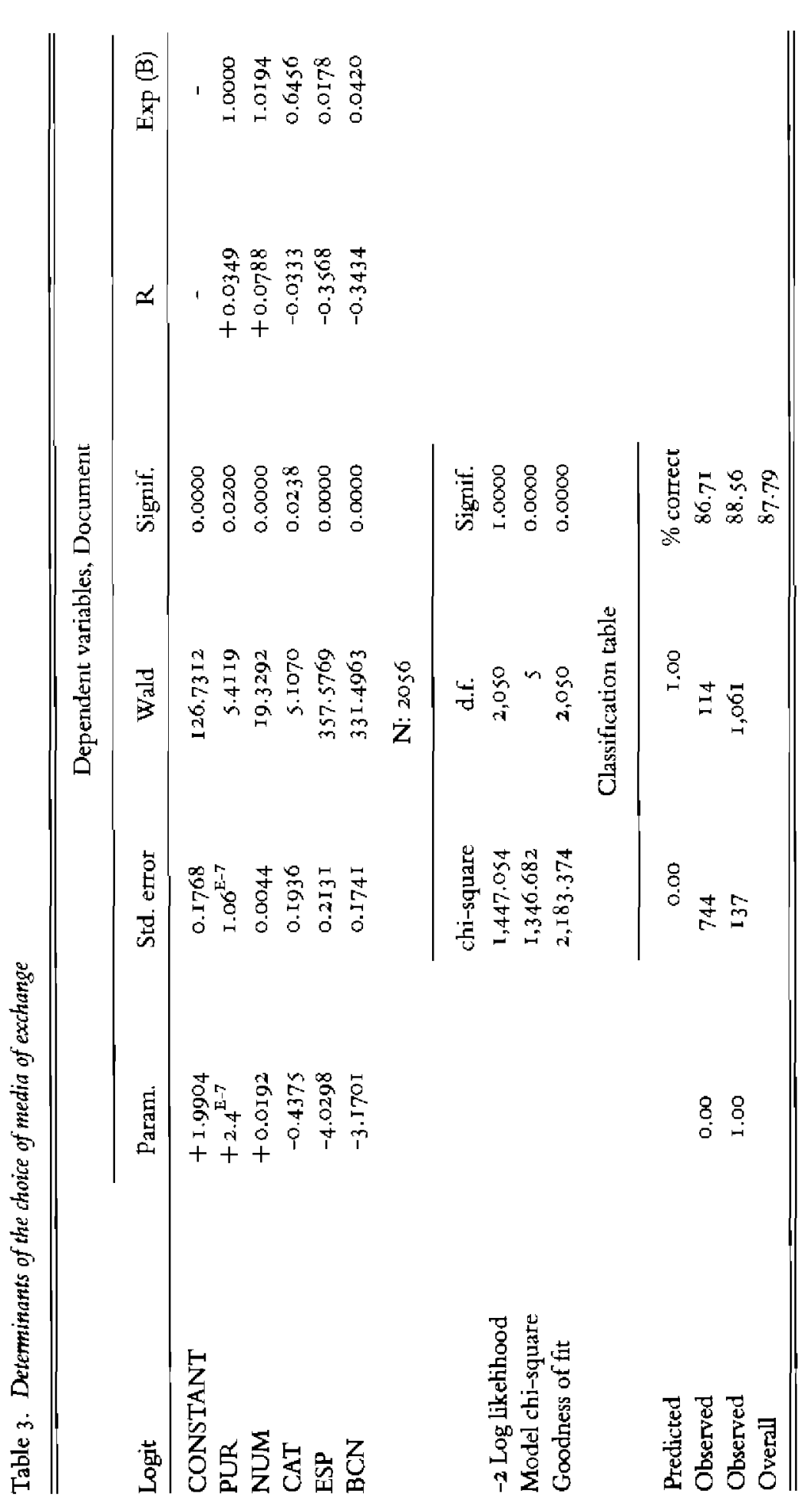


partial contribution to the model is less relevant. Finally, note that the different measures of the goodness of fit of the whole model are satisfactory with the hypothesis that this model fits well the available data.

All documents, which were used as substitutes for money, can be classified within two different categories. First, there were documents which had to be paid some days after their presentation to the person who initially issued them (unsigned documents). Second, there are those which had to be paid at a particular date (documents signed by the debtor). In general terms, the first type were far easier to transfer than the second because they did not have a deadline beyond which the legal enforcement of the payment was much more difficult. The second type of documents had stronger legal protection before the deadline date because they were signed by the debtor himself. Consequently, it could be said that, while the first type of documents had a liquidity advantage (easy transfer), the second were safer from the point of view of legal protection.

The second of our models analyses how the choice of media of exchange can be related to these intrinsic characteristics of the documents used as money. A subsample of our database has been taken, consisting of all operations where agents used documents other than currency to cancel debts (I,I98 observations). The dependent variable is a dichotomic variable indicating whether transactions were undertaken with either unsigned documents or signed documents. The variable takes the value one if the document was signed by the debtor and zero otherwise. The model is as follows:

$$
\operatorname{Prob}\left(\mathrm{SIGNED}_{\mathrm{I}}=\mathrm{I}\right)=\mathrm{f}(\alpha+\beta \mathrm{PTA}+\gamma \mathrm{DAY}+\delta \mathrm{EsP}+\mu)
$$

According to this model, the probability that the cancellation of a debt was made with a signed document, that is, a document which had to be paid before a particular date specified in it, is a function of the following variables:

PTA, a variable that measures the value of the debt generated in each of the operations;

DAY, a variable that measures the number of days that passed between the day when the document was received by the firm and the first day when the firm was paid;

and Esp, which has been previously described.

The expected outcome of the estimation of the model was that the probability that payment took place with a signed document would be a positive function of the variables PTA, DAY and EsP. It was expected that PTA would be positively related with the dependent variable because as the amount of the debt involved rose, it became more important to obtain a safe payment rather than an easily transferable asset. Likewise, DAY was also expected to be positively correlated with the dependent variable because firms would have only been willing to accept signed documents in cases when the date of payment (after which the document lost part of its legal enforceability) was late enough. In fact, it could be said that signed documents are mostly instruments of credit rather than strict means of payment. The coefficient of the variable Esp was also expected to be positive. However, this is due to the particular firm studied, which was located in Esparreguera, having contracts with some of its customers of which signed documents were a part. Apart from this aspect of this particular firm's business, we had no other reason for expecting differences among the different firms in our sample.

The results of the estimation of this second model are contained in Table 4. All the estimated coefficients of the variables have the expected signs and are significantly different from zero (as shown in column Signif.). When the R column is inspected, it will be seen that the variable DAY has the most important partial explanatory contribution to the model. Notice that the other variables are significant but theit partial contribution to the model is less relevant. Finally, it should be noted that the different measures of the goodness of fit of the whole model are satisfactory with the hypothesis that the model fits the available data well.

$\mathrm{V}$

This paper has analysed the main determinants of the use of different assets as media of exchange in Catalonia from I 844 to 1874 . The main hypothesis has been that, during this period, the Catalan economy grew rapidly in the absence of sufficient legal currency. In this context, media of exchange, other than coins and legal notes, were employed by economic agents to carry out their commercial exchanges. Thus bills of exchange and other privately-issued documents were used extensively as means of payment. Although bills of exchange lacked many of the qualities that would make them the most 'natural' universally accepted medium of exchange, the uncoordinated behaviour of agents in their commercial relationships resulted in the extensive circulation of these documents. They were widely accepted by many firms as means of settling debts.

The empirical analysis has shown that the main determinants for the acceptance of documents, other than legal currency, were, in the first place, the relative scarcity of universally acceptable legal currencies and, in the second place, the particular characteristics of the commercial counterpart who passed the bill as payment for his debt. Thus acceptability of media of exchange, other than legal money, was strongly related to variables which are indicative of long-term commercial relationships and, consequently, higher levels of confidence and good reputation between trade partners. It has also been possible to show which variables affected the type of document that was accepted as medium of exchange. Signed documents were preferred in transactions involving sizeable amounts and also when the date of payment was late enough with respect to the date of receipt.

The number of suggestions for further research that arises in these topics is very large. First, and from a theoretical viewpoint, it would be very interesting to introduce ideas of personal reputation in long-lasting commercial relationships within the context of the search-theoretical models of money. This seems to us the 
appropriate context in which episodes, such as that considered here or free-banking regimes that were commonplace in many countries during the mineteenth century, can be understood from an analytical perspective. Second, it is worth investigating whether the Catalan experience, or that of Lancashire previously investigated by Ashton, ${ }^{20}$ are representative of the situation of the monetary market in other countries during industriahsation. The availability of more, and better, data from individual firms is necessary to test whether bills of exchange (and similar documents) played a role as media of exchange. Related to this last point, it would be very interesting to study time series of currency supply in order to link them with the circulation of bills of exchange as money. This would allow an understanding of whether bills of exchange were more easily acceptable when currency was relatively more scarce. One could test in this fashion whether there is a mechanism built into the economy that allows it to create its own supply of media of exchange, partly independent of the creation of currency. It appears appropriate to reformulate the concept of monetary supply and its part in the analysis of industrialisation and economic growth. We beheve that we have given some evidence indicating that traditional measures of monetary supply may be too narrow. Furthermore, the role of monetary restrictions in economic growth should be revised because our analysis seems to suggest that agents may be able to overcome this type of constraint. We do not know whether this system of exchange, partly based on the circulation of privately-issued documents, such as bills of exchange, was very efficient compared with an alternative system, based on fully available universal media of exchange. These and related questions can only be answered by considering a theoretical model of monetary exchange which examines the possible welfare gains of loosening monetary constraints. Third, we think that explanations of mid-nineteenthcentury Spanish price stability, based on arguments such as bimetallism, need careful re-examination in the light of some of our arguments. All these considerations are left to further research. 